\title{
Macro-/micro-coupling regulation of nanoporous metals via vapor phase alloying-dealloying
}

\author{
Yujun Shi, Ying Zhang, Jingyu Qin and Zhonghua Zhang*
}

\begin{abstract}
Nanoporous metals with bicontinuous ligament-channel structure are of great importance in catalysis, electro-catalysis, actuation and energy storage and conversion. However, the intrinsic brittleness of nanoporous metals has always been the "Achilles heel" that impedes their practical applications. Utilizing the vapor pressure difference of metals, herein we propose a flexible and general vapor phase alloying (VPA)-dealloying strategy to fabricate nanoporous layers supported on the substrates with the same element. By adjusting the VPA time and temperature, the thickness and microstructure control over nanoporous layers can be realized by combining with diverse dealloying methods. Besides, various metals including $\mathrm{Ag}, \mathrm{Au}, \mathrm{Cu}, \mathrm{Co}$ and $\mathrm{Ni}$ with different macro sizes and shapes can be fabricated into nanoporous structures through this method. More importantly, the greatly improved tensile ductility owing to the nanoporous layersubstrate structure and well enhanced catalytic performance for hydrogen evolution reaction of the as-fabricated nanoporous metals signify great potentials of the VPA-dealloying strategy for practical applications.
\end{abstract}

Keywords: nanoporous metals, vapor phase alloying-dealloying, macro and micro regulation of nanostructure, dealloying mechanism, mechanical properties

\section{INTRODUCTION}

Nanoporous metals have recently aroused great interests because they not only maintain the features of bulk metals such as excellent thermal/electrical conductivity but also gain numerous intriguing properties of nanostructures including large specific surface area, novel size effect, fast mass transport, highly efficient catalytic activity and significantly enhanced kinetics $[1,2]$. Numerous nanoporous metals such as $\mathrm{Au}, \mathrm{Pd}, \mathrm{Pt}, \mathrm{Ag}, \mathrm{Cu}, \mathrm{Co}, \mathrm{Ni}$ [3-11] and their alloys [12-16] have been fabricated by dealloying and show tremendous potentials in electrocatalysis [17-19], actuation [20,21], surface-enhanced Raman scattering [22], supercapacitors [23] and energy storage and conversion [24]. Dealloying is an important route to fabricate nanoporous metals, which involves the selective dissolution of non-noble element(s) and diffusion/re-organization of noble metal atoms. Several dealloying methods have been developed, including conventional chemical/ electrochemical dealloying [3,25-28], liquid metal dealloying [29-31], electrolytic dealloying in non-aqueous electrolytes [23,32] and vapor phase dealloying (VPD) $[5,33]$. These dealloying techniques are all effective and have their respective advantages, which extend the range of nanoporous metals from noble metals to transition metals and even refractory metals.

Freestanding nanoporous metals always show no tensile plasticity and cannot be bent flexibly [34,35]. Consequently, the intrinsic brittleness becomes the "Achilles heel" of nanoporous metals that enormously impedes their structural and functional applications, and thus improving the ductility of nanoporous metals becomes an enormous challenge and central science issue [36,37]. To address this issue, a strategy was proposed by Wang and Weissmüller [38] to impregnate the nanoporous metal with a polymer, which indeed improved the ductility of nanoporous gold as manifested by three-point bending. Unfortunately, this approach was also accompanied with the partial loss of structural and functional properties of nanoporous metals. It is worth noting that in a filmsubstrate system, a polymer substrate (for example, polyimide) can significantly improve the ductility of metal films which have good adhesion with the substrate by delocalizing deformation in the film [39]. Moreover, through enhancing the adhesion between the film and substrate, adhesion layers could further retard the strain localization and the metal films on polymer substrates could be stretched beyond 50\% [40]. When directly ap-

Key Laboratory for Liquid-Solid Structural Evolution and Processing of Materials (Ministry of Education), School of Materials Science and Engineering, Shandong University, Jinan 250061, China

* Corresponding author (email: zh_zhang@sdu.edu.cn) 
plied to gradient nano-grained films, the above principle remarkably improves the yield strength and tensile ductility of nano-grained metal that is intrinsically brittle [41]. Taking advantage of the ductility enhancement principle of the film-substrate system, formation of a nanoporous layer on a ductile metal substrate will be a feasible solution to solve the intrinsic brittleness issue of nanoporous metals. However, under the precondition of ensuring the strong interfacial adhesion, it remains a great challenge to fabricate the nanoporous layer on the surface of the metal substrate and realize the thickness control of the nanoporous layer simultaneously.

In this work, utilizing the vapor pressure difference of metals, we developed a vapor phase alloying (VPA)dealloying strategy to fabricate nanoporous metals, during which the precursors were synthesized at the saturated vapor of the metals with low evaporation temperatures (here, $\mathrm{Zn}$ ). Because of the great flowability and reactivity of metallic vapor, the thickness and microstructure control over nanoporous layers with arbitrary shapes supported on the metal substrates can be realized combining with diverse dealloying methods. The same element of nanoporous layer and substrate can guarantee the strong interfacial adhesion and good modulus match, which are two key factors to achieve the constraint of the substrate to the nanoporous layer and improve the ductility of nanoporous metals. In addition, the VPA-dealloying strategy is a flexible and universal method to fabricate nanoporous metals with different macro sizes and shapes. More importantly, the good tensile mechanical properties and the greatly enhanced catalytic activity of the obtained nanoporous metals manifest their potentials in practical applications.

\section{EXPERIMENTAL SECTION}

\section{Sample preparation}

To realize surface alloying of metals, $\mathrm{Zn}$ powder (purity: $99.9 \mathrm{wt} \%$ ) was chosen as the sacrificing metal because of its lower evaporation temperature than those of most metals and earth abundance. Before the VPA, commercial Ag foil (purity: $99.99 \mathrm{wt} \%$; thickness: 50 or $200 \mu \mathrm{m}$ ), Co foil (purity: $99.99 \mathrm{wt} \%$; thickness: $200 \mu \mathrm{m}$ ), Ni foil (purity: $99.99 \mathrm{wt} \%$; thickness: $100 \mu \mathrm{m}$ ), Cu foil (purity: $99.99 \mathrm{wt} \%$; thickness: $200 \mu \mathrm{m}$ ), Ag wire (purity: $99.99 \mathrm{wt} \%$; diameter: $200 \mu \mathrm{m}$ ), Ag bulk (purity: $99.99 \mathrm{wt} \%$; size: $5 \times 5 \times$ $2 \mathrm{~mm}^{3}$ ), Au wire (purity: $99.99 \mathrm{wt} \%$; diameter: $50 \mu \mathrm{m}$ ) and $\mathrm{Ni}$ foam (purity: $99.9 \mathrm{wt} \%$ ) were rinsed by acetone, alcohol and dried in vacuum to remove the contamination on the surface. Here the fabrication of Ag- Zn surface alloys was chosen as an example to illustrate the VPA process. The $\mathrm{Zn}$ powder with a mass of $1 \mathrm{~g}$ was first put into the bottom of a quartz tube to make sure the $\mathrm{Zn}$ powder was sufficient for the VPA process and Ag foil was fixed at the middle of the quartz tube without directly touching with $\mathrm{Zn}$ powder. Then, the quartz tube was purged by Ar and pumped to vacuum repeatedly for at least 5 times, and sealed by hydrogen flame. Finally, the quartz tube was heated in a resistance furnace at a series of temperatures for different times to proceed the VPA.

To obtain nanoporous metals, various dealloying methods were adopted. Electrochemical dealloying was performed in a $0.1 \mathrm{~mol} \mathrm{~L}^{-1} \mathrm{H}_{2} \mathrm{SO}_{4}$ solution on a CHI760E potentiostat in a standard three-electrode cell at ambient temperature. Saturated calomel electrode (SCE), graphite rod and precursor alloys served as the reference electrode, counter electrode and working electrode, respectively. Before electrochemical dealloying, linear sweep voltammetry (LSV) was conducted at a scan rate of $5 \mathrm{mV} \mathrm{s}^{-1}$ to determine the dealloying potential. Then the potentiostatic dealloying was performed until the current density decreased abruptly. Nanoporous metals were also obtained by chemical dealloying or VPD. The detailed dealloying procedures are given in the Supplementary information.

\section{Microstructural characterization}

$\mathrm{X}$-ray diffraction (XRD) measurements of all samples were performed on an XD-3 diffractometer (Beijing Purkinje General Instrument Co., Ltd, China) with $\mathrm{Cu} \mathrm{K} \alpha$ radiation. The microstructures and chemical compositions were characterized by a scanning electron microscope (SEM, ZEISS SIGMA300) equipped with an energy dispersive X-ray (EDX) analyzer. The ligament size of nanoporous metals was evaluated using the Nano Measure software by manually measuring at least 200 ligaments in SEM images. In addition, a home-made sample holder with flowing corrosion solutions was adopted for in-situ XRD of dealloying.

\section{Mechanical and electrocatalytic measurements}

The hardness and elastic modulus of nanoporous Ag were tested by the TriboIndenter (TI980) with a calibrated Berkovich diamond tip. During the experiments, the loading rate was set as $200 \mu \mathrm{N} \mathrm{s}^{-1}$ and the maximum load was $1000 \mu \mathrm{N}$. And the holding time and loading/unloading time were 2 and $5 \mathrm{~s}$, respectively. The distance between indents was at least three times larger than the size of indents. For each sample, at least three loaddisplacement curves were repeatedly conducted to ensure 
the accuracy of data. The tensile tests were performed on an electronic universal testing machine (CMT6103) at a constant strain rate of $5 \times 10^{-4} \mathrm{~s}^{-1}$. For hydrogen evolution reaction (HER), LSV was recorded in a $\mathrm{N}_{2}$-saturated $1 \mathrm{~mol} \mathrm{~L}^{-1} \mathrm{KOH}$ solution in the three-electrode cell with pristine $\mathrm{Ni}$ foam or nanoporous $\mathrm{Ni}$ foam as the working electrode at a scan rate of $5 \mathrm{mV} \mathrm{s}^{-1}$. $\mathrm{An} \mathrm{Ag} / \mathrm{AgCl}$ electrode (in a saturated $\mathrm{KCl}$ solution) and graphite rod were used as the reference electrode and counter electrode, respectively.

\section{RESULTS AND DISCUSSION}

Fig. 1 shows the schematic illustration for the fabrication processes of nanoporous metals through the VPA-dealloying strategy. In a vacuum environment, when heated to the temperature above the evaporation temperature of $\mathrm{N}$-metal while below M-metal, the N-metal will transform to vapor while the M-metal can keep stable. As a result, an alloy layer forms on the M-metal surface because of the gas-solid reaction induced by the diffusion between the two kinds of metals. Noticeably, the shape of
M-metal is flexible and not only limited to foils. The thicknesses and phase compositions of the alloy layer can be controlled by adjusting the temperature and time of VPA. After alloying, chemical or electrochemical dealloying can be conducted to obtain nanoporous $\mathrm{M}$ utilizing the difference of chemical/electrochemical activity of metals. For some refractory metals or transition metals that are prone to be oxidized, nanoporous $\mathrm{M}$ can also be fabricated by VPD. Eventually, the nanoporous layers supported on the metal substrates with different shapes such as foil, wire, bulk and even foam can be obtained after the VPA-dealloying processes. From the perspective of improving mechanical properties (especially ductility) of nanoporous metals, this strategy could guarantee good modulus match between the nanoporous layer and substrate (the same metal) and nice interfacial adhesion (insitu surface alloying-dealloying).

In order to explore the growth mechanism of the alloy layer during VPA, we take the Ag-Zn system as an example due to the following reasons. First, because of the large difference in saturated vapor pressures of $\mathrm{Zn}$ and $\mathrm{Ag}$

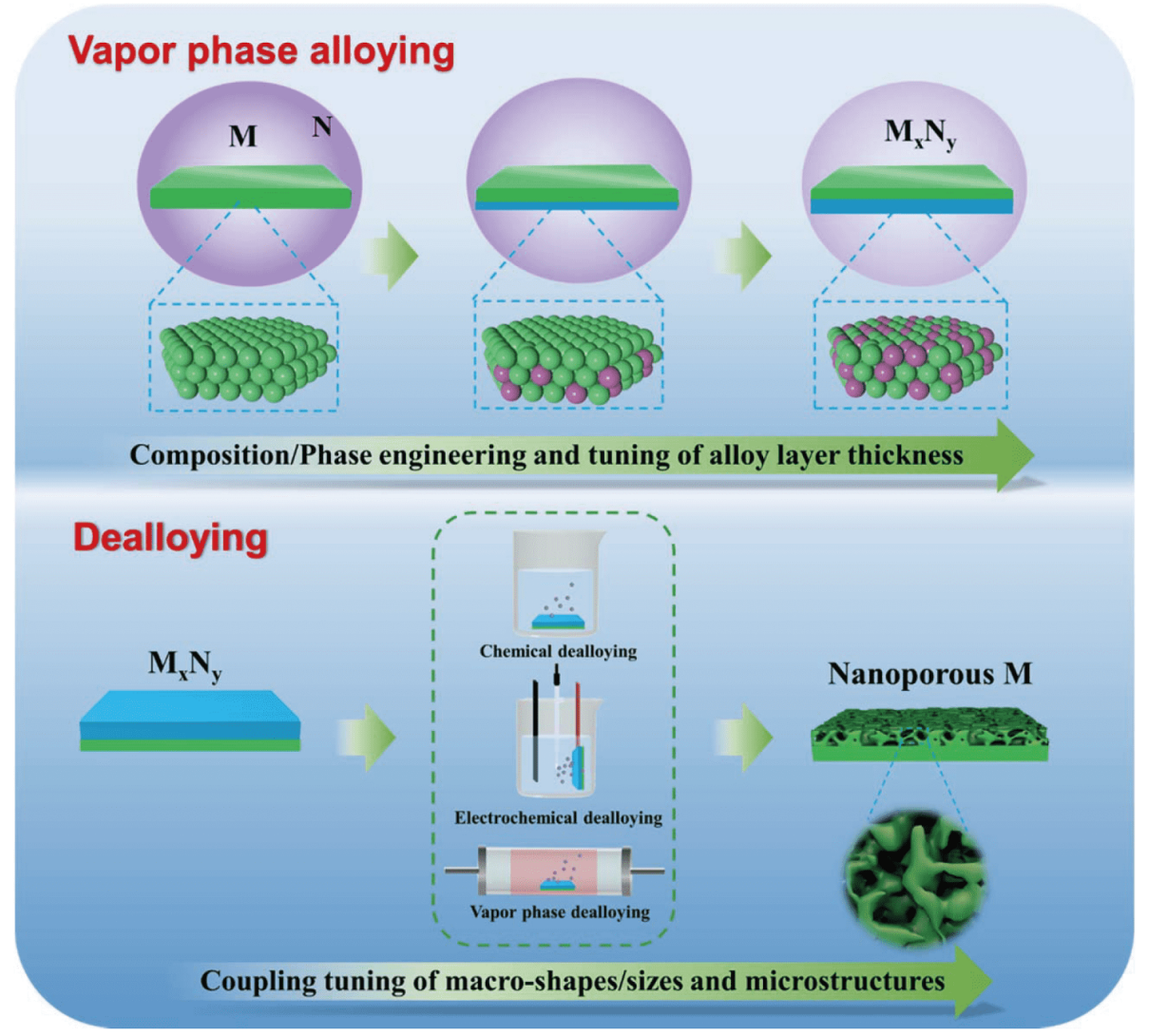

Figure 1 The schematic illustration showing the fabrication strategy of nanoporous metals supported on the metal substrates by the combination of VPA with subsequent dealloying. 

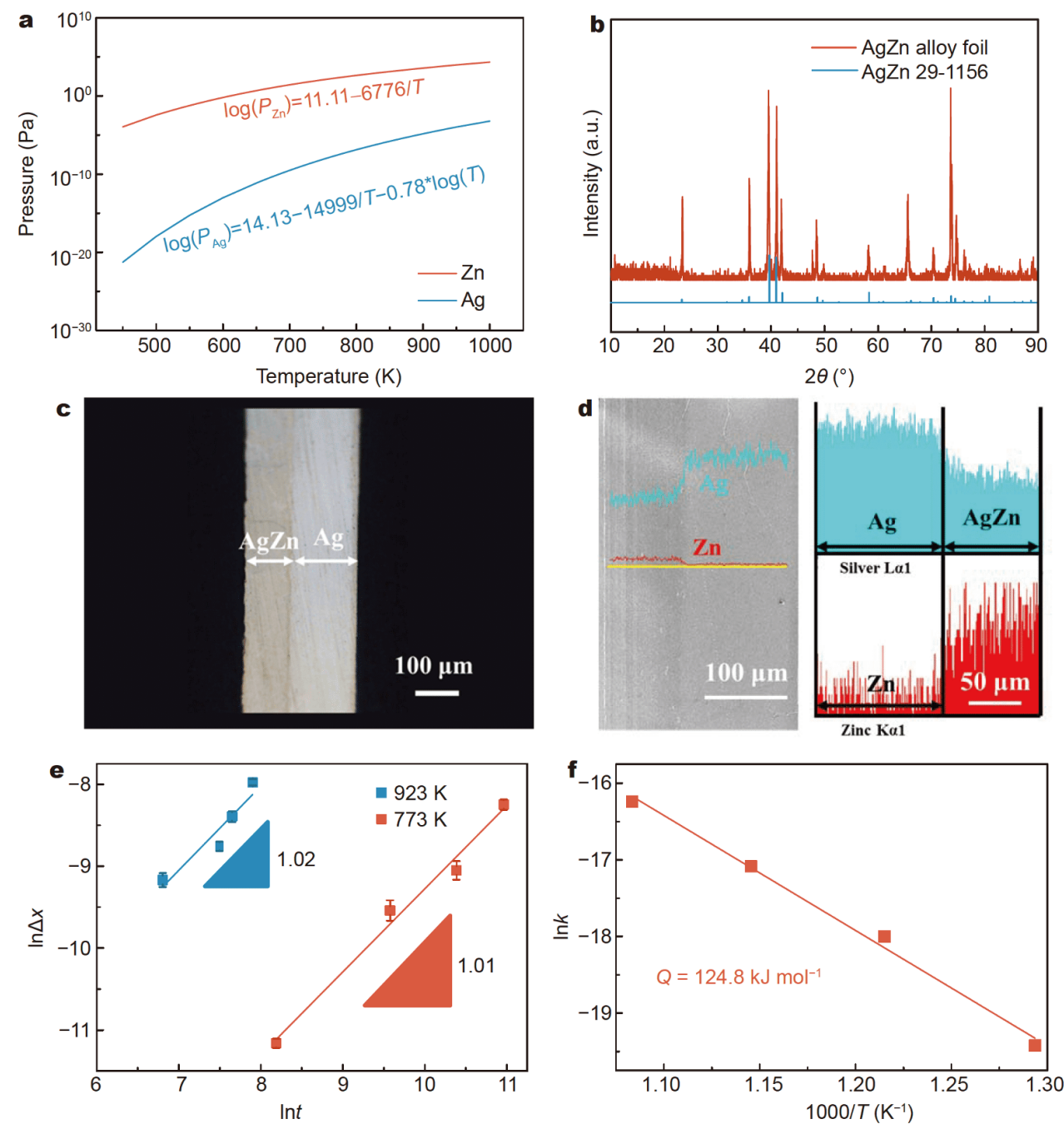

Figure 2 (a) The temperature dependence of the saturated vapor pressures of $\mathrm{Zn}$ and Ag. (b) The typical XRD pattern of the AgZn alloy layer after VPA at $923 \mathrm{~K}$ for $15 \mathrm{~min}$. (c) The optical microscope photograph of the alloy layer after VPA at $923 \mathrm{~K}$ for $15 \mathrm{~min}$. (d) SEM image of the cross-section and the line-scan result of the sample corresponding to (c). (e) Plot of $\ln \Delta x$ versus $\ln t$ for VPA at different temperatures. (f) Plot of $\ln k$ versus the reciprocal temperature to determine the activation energy for the AgZn layer growth.

(Fig. 2a) [42], there is a wide temperature range and vacuum condition where $\mathrm{Zn}$ powder can be sublimated into vapor while Ag foil is stable and keeps its original shape. Second, the interface between the alloy layer and pristine Ag substrate is optically evident so that the thickness of the alloy layer can be measured by optical microscopy [43]. Third, nanoporous Ag is an ideal catalyst for various energy conversion reactions after dealloying [44-46]. Here, the Ag foil with a thickness of $200 \mu \mathrm{m}$ was chosen as the substrate for VPA. Consistent with the Ag- Zn phase diagram (Fig. S1) [47], the typical pattern in Fig. 2b illustrates the AgZn phase (PDF \# 29-1156) first forms on the surface of the Ag foil at the early stage of VPA. After
VPA at $923 \mathrm{~K}$ for $15 \mathrm{~min}$, the thickness of the AgZn layer is $104 \pm 8 \mu \mathrm{m}$, and there is a fairly obvious interface between the alloy layer and the Ag substrate (Fig. 2c). The SEM image and the line-scan result in Fig. $2 \mathrm{~d}$ further illustrate that the $\mathrm{Zn}$ and $\mathrm{Ag}$ contents show an abrupt variation in the interfacial zone, but keep stable in the AgZn alloy layer. With the VPA time extending to 30,35 and $45 \mathrm{~min}$, the thicknesses of the alloy layers increase to $156 \pm 9,222 \pm 12$ and $343 \pm 12 \mu \mathrm{m}$, respectively (Fig. S2a). Moreover, the contents of $\mathrm{Zn}$ and $\mathrm{Ag}$ are constant throughout the whole cross-section of the asalloyed sample after VPA for $45 \mathrm{~min}$ (Fig. S2b). The present results demonstrate that AgZn is the single alloy 
phase at the early stage of VPA and only after the whole $\mathrm{Ag}$ foil transforms to $\mathrm{AgZn}$, other alloy phases with higher $\mathrm{Zn}$ content such as $\mathrm{Ag}_{5} \mathrm{Zn}_{8}$ or $\mathrm{AgZn}_{3}$ can appear. For further analyzing the rule of thickness variation, the VPA between the Ag foil and $\mathrm{Zn}$ powder was conducted at the lower temperatures of 773,823 and $873 \mathrm{~K}$. As shown in Fig. S3, the thicknesses of AgZn layers increase with the extension of time at $773 \mathrm{~K}$. Nevertheless, the growth rate of the alloy layer is much slower than that at $923 \mathrm{~K}$, and more than $16 \mathrm{~h}$ is necessary for the $\mathrm{Ag}$ foil to completely react with the $\mathrm{Zn}$ vapor to form AgZn. This scenario matches well with the Fick's law of diffusion and illustrates that the thickness of alloy layer can be facilely modulated by optimizing the VPA temperature and time.

It is known that the relationship between the thickness of reaction layer $(\Delta x)$ and diffusion time $(t)$ can be described by the following equations $[48,49]$ :

$\Delta x=k t^{n}$,

$\ln \Delta x=n \ln t+\ln k$,

where $k$ is the rate constant and $n$ is the kinetic exponent. The average thickness variations of AgZn layers at 773 and $923 \mathrm{~K}$ were measured and summarized in Tables S1 and S2. Clearly, a good linear relationship between $\ln \Delta x$ and $\ln t$ can be obtained at different alloying temperatures in Fig. 2e. The $n$ values were calculated to be 1.01 and 1.02 at 773 and $923 \mathrm{~K}$, respectively. The growth mechanisms of intermetallic compounds can be classified into two types, reaction-controlled $(n=1)$ and diffusioncontrolled $(n=0.5)$ [50-52]. Therefore, the growth of $\mathrm{AgZn}$ layer is governed by the reaction-controlled mechanism. This result is consistent with the reaction-controlled process of Ti-Al system [50,52], but different from the diffusion-controlled formation of intermetallic compounds in the Ag- $\mathrm{Zn}$ couple at 573-623 K [43]. The activation energy $(Q)$ for the reaction-controlled growth process can be assumed to follow an Arrhenius relation at different temperatures $(T)$,

$k=k_{0} \exp \left(-\frac{Q}{R T}\right)$,

$\ln k=\ln k_{0}-\frac{Q}{R T}$,

where $k_{0}$ is a temperature-independent constant, and $R$ is the gas constant. The values of $\ln k$ and $T$ are listed in Table S3. According to Equation (4), $\ln k$ is plotted versus reciprocal temperature in Fig. 2f, which follows a good linear correlation. The slope of the line represents $-Q / R$, so the activation energy was calculated as $124.8 \mathrm{~kJ} \mathrm{~mol}^{-1}$, which is much higher than $58.1 \mathrm{~kJ} \mathrm{~mol}^{-1}$ in the $\mathrm{Ag}-\mathrm{Zn}$ system for a diffusion-controlled process at temperatures between 573 and $623 \mathrm{~K}$ [43]. The different growth mechanisms (reaction-controlled versus diffusion-controlled) and reaction types (vapor-solid versus solid-solid) account for the discrepancy in the activation energy.

As mentioned above, the thickness of Ag- $\mathrm{Zn}$ alloy layer can be controlled by modulating the VPA time and/or temperature. Thus, nanoporous Ag supported on the Ag substrate can be fabricated by dealloying the Ag-Zn layer, and its thickness could be effectively regulated (Fig. 3). With prolonging VPA time, the thickness of the porous Ag layer increases (Fig. 3a-f). Furthermore, the nanoporous structure runs across the entire section of the foil for the VPA time of $16 \mathrm{~h}$ (Fig. 3c). The XRD and EDX results in Fig. S4 illustrate that almost all $\mathrm{Zn}$ atoms in the AgZn layer were leached away. The thickness of the nanoporous layer is about 75,120 and $280 \mu \mathrm{m}$ at $773 \mathrm{~K}$ for the VPA time of 4,9 and $16 \mathrm{~h}$, respectively, corresponding well with that of the alloy layer in Fig. S3. Additionally, the average ligament size of nanoporous Ag is determined to be $0.56 \pm 0.12 \mu \mathrm{m}$ for the VPA time of $4 \mathrm{~h}$ (Fig. 3d, g), but decreases to $0.36 \pm 0.08$ and $0.30 \pm$ $0.06 \mu \mathrm{m}$ with the VPA time prolonging to 9 and $16 \mathrm{~h}$, respectively (Fig. 3h, i). Notably, the nanoporous structure becomes more open and uniform with increasing VPA time, which is probably associated with the higher $\mathrm{Zn}$ content in the alloy layer for the longer VPA time owing to the non-stoichiometric nature of AgZn phase (Fig. S1).

According to the phase diagram (Fig. S1), several intermetallic compounds ( $\beta-\mathrm{AgZn}, \gamma-\mathrm{Ag}_{5} \mathrm{Zn}_{8}$, and $\varepsilon-\mathrm{AgZn}_{3}$ ) exist in the $\mathrm{Ag}-\mathrm{Zn}$ system. The $\mathrm{Ag}$ foils $(50 \mu \mathrm{m}$ in thickness) were used to investigate the VPA-induced phase evolution in the Ag-Zn system. Only the AgZn phase can be identified after VPA for 4 and $9 \mathrm{~h}$ at $773 \mathrm{~K}$ (Fig. S5). $\mathrm{Ag}_{5} \mathrm{Zn}_{8}$ and $\mathrm{AgZn}_{3}$ appear in turn after prolonging the alloying time to 16 and $25 \mathrm{~h}$, which suggests that the phase compositions can be precisely controlled by modulating the VPA time. Nanoporous Ag foils were thus obtained by potentiostatic dealloying of these Ag-Zn precursors with different phase compositions (Fig. 4a-c, Figs S6a and S7). For the nanoporous Ag dealloyed from AgZn, the ligaments show good connection, but the connecting degree of ligaments decreases with increasing $\mathrm{Zn}$ content in the $\mathrm{Ag}$ - Zn precursors. And loose connection is observed in the sample dealloyed from $\mathrm{AgZn}_{3}$ (Fig. 4c). Accordingly, the porosity in nanoporous Ag obviously improves with the increase of $\mathrm{Zn}$ in the Ag-Zn precursors (Fig. S7). Fig. S6b and Fig. $4 d-f$ show the size distributions of ligaments in the obtained nanoporous $\mathrm{Ag}$, and the average ligament size shows a 


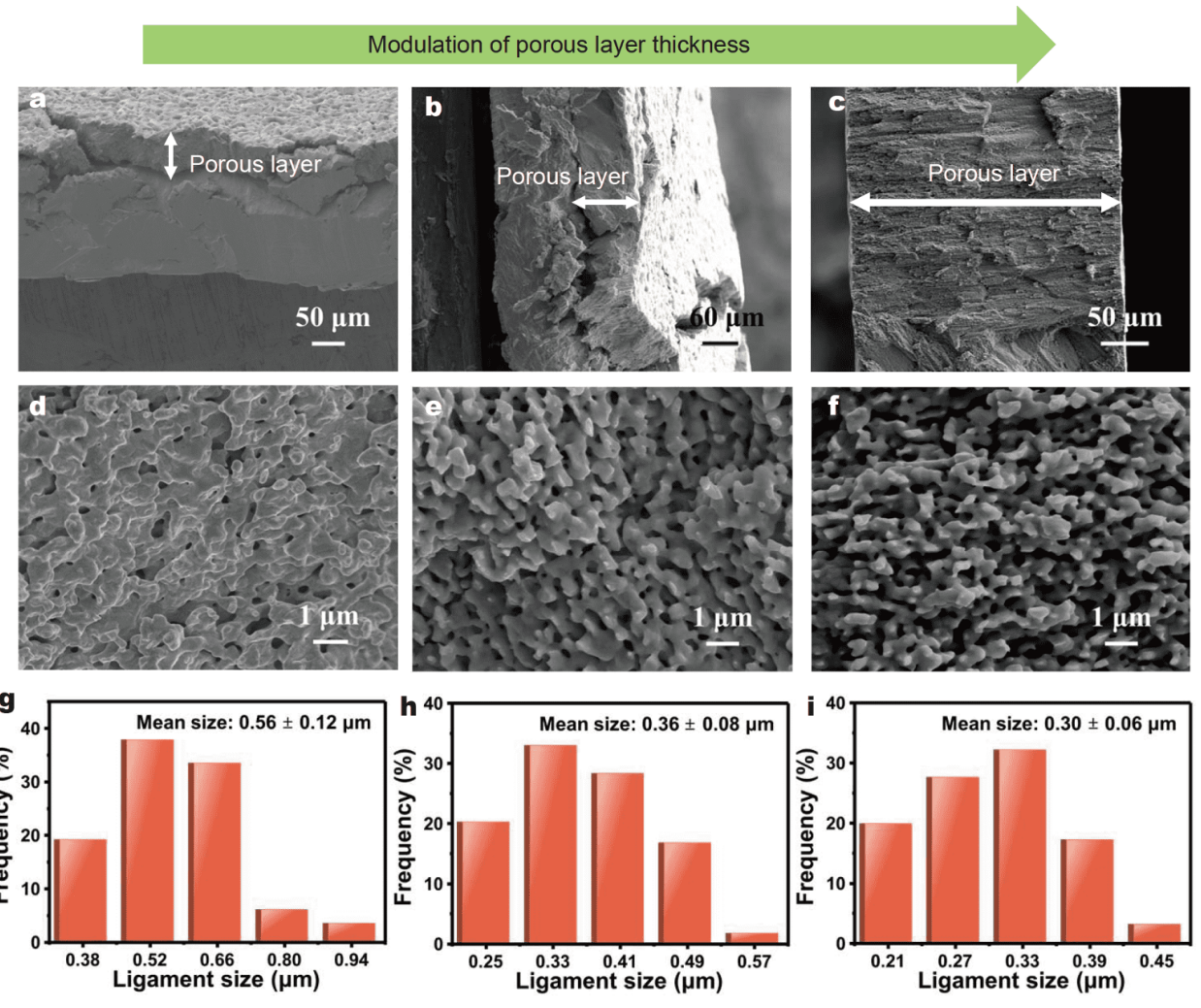

Figure 3 Cross-sectional SEM images showing the microstructures of nanoporous Ag fabricated through potentiostatic dealloying of the AgZn alloy phase at $773 \mathrm{~K}$ for different VPA times of (a, d) 4, (b, e) 9 and (c, f) $16 \mathrm{~h}$ (the pristine thickness of Ag foil is $200 \mu \mathrm{m}$ ). The columnar plots in (g, h and i) show the characteristic length scales of nanoporous Ag corresponding to (d, e, and f), respectively.

downtrend with the phase evolution in the Ag-Zn precursors (Fig. 4g). In addition, the typical XRD pattern verifies that the as-dealloyed sample is composed of the single face-centered cubic (fcc) Ag phase, and the obtained nanoporous Ag foil maintains a good self-supporting property (Fig. $4 \mathrm{~h}$ and inset). Through the VPAdirected phase engineering in the Ag- Zn system, the microstructures of nanoporous Ag including the connecting degree of ligaments, the porosity and the average ligament size could be effectively regulated, which are crucial factors influencing mechanical properties of nanoporous metals $[37,53,54]$.

Thanks to the effect of temperature and time on VPA, we also synthesized the $\mathrm{AgZn}_{3}$ precursors from the $\mathrm{Ag}$ foil of $50 \mu \mathrm{m}$ in thickness at different temperatures ( $773 \mathrm{~K}$ for $25 \mathrm{~h}, 823 \mathrm{~K}$ for $16 \mathrm{~h}, 873 \mathrm{~K}$ for $4 \mathrm{~h}$ and $923 \mathrm{~K}$ for $50 \mathrm{~min}$ ), Fig. 4i. After potentiostatic dealloying, the obtained nanoporous Ag foils exhibit a similar bicontinuous ligament-channel structure (Fig. S8). Fig. 4i shows the average ligament size of these nanoporous $\mathrm{Ag}$ foils, as well as the temperature dependence of VPA time to form
$\mathrm{AgZn}_{3}$. As temperature increases, the VPA time to obtain $\mathrm{AgZn}_{3}$ gradually decreases owing to the accelerating diffusion of both $\mathrm{Ag}$ and $\mathrm{Zn}$ at higher temperatures. The average ligament size is $0.15 \pm 0.03,0.14 \pm 0.02,0.20 \pm$ 0.04 and $0.21 \pm 0.04 \mu \mathrm{m}$ for nanoporous $\mathrm{Ag}$ fabricated by dealloying of the $\mathrm{AgZn}_{3}$ precursors obtained at 773,823 , 873 and $923 \mathrm{~K}$, respectively, which shows a slight change with the VPA temperature. Obviously, VPA at higher temperatures could lead to rapid formation of desired precursors, without sacrificing the large porosity and small ligaments of the nanoporous structure after dealloying.

In-situ XRD was further conducted to explore the dealloying mechanism and the chemical dealloying of $\mathrm{AgZn}_{3}$ at a constant flow of $4 \mathrm{~mol} \mathrm{~L}^{-1} \mathrm{HNO}_{3}$ was taken as an example (Fig. 5a, b). Before the dealloying, all the peaks are well indexed to $\mathrm{AgZn}_{3}$. At the early stage of dealloying, the peak intensity of $\mathrm{AgZn}_{3}$ weakens as time increases, without other peaks being observed. While after $200 \mathrm{~min}$, the peaks of $\mathrm{Ag}$ located at $38.12^{\circ}, 44.28^{\circ}$, $64.43^{\circ}, 77.47^{\circ}$ and $81.54^{\circ}$ appear and strengthen con- 


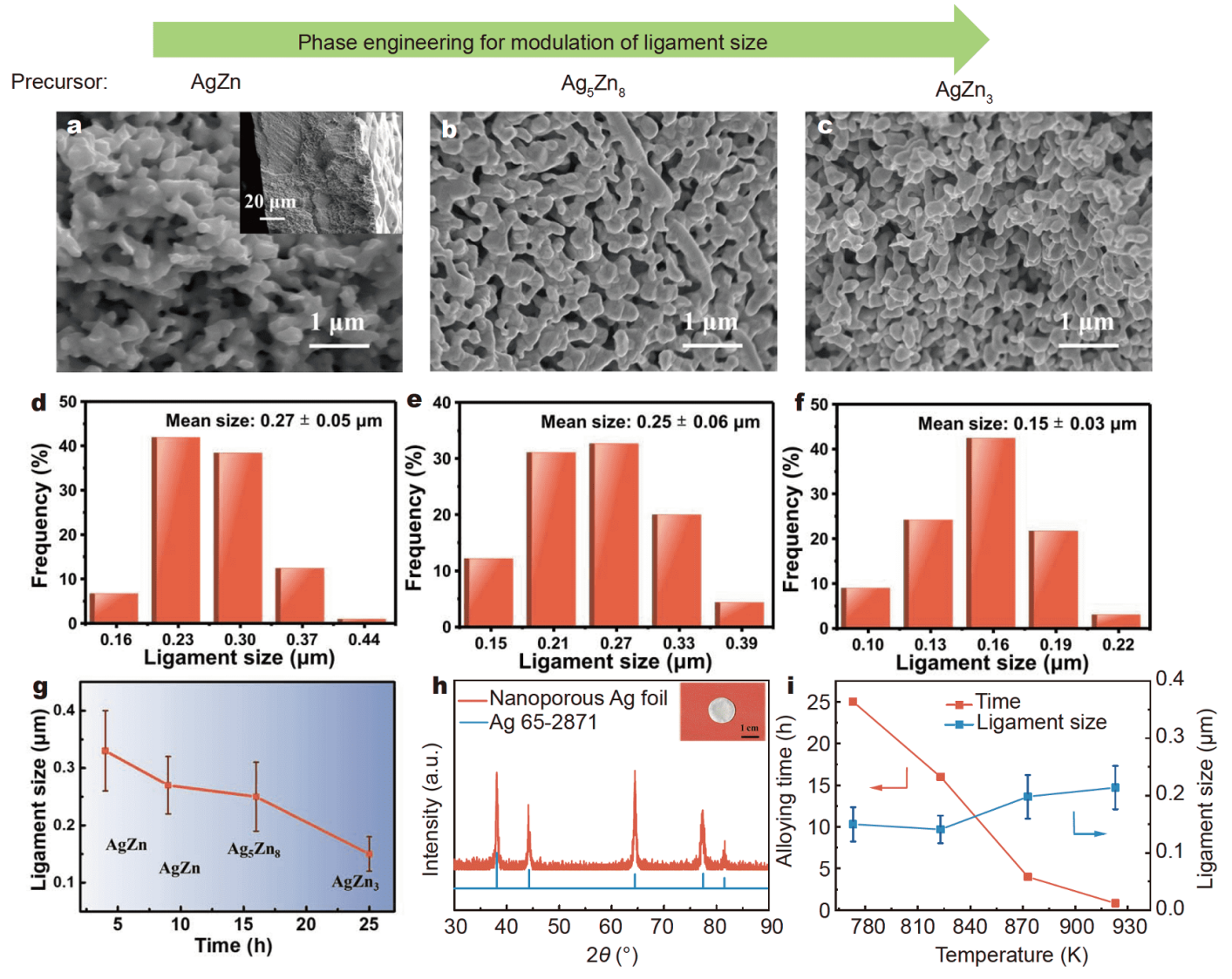

Figure 4 Cross-sectional SEM images showing the microstructures of nanoporous $\mathrm{Ag}$ fabricated by potentiostatic dealloying of the $\mathrm{AgZn} \mathrm{Ag}_{5} \mathrm{Zn}_{8}$ and $\mathrm{AgZn}_{3}$ precursors obtained through VPA at $773 \mathrm{~K}$ for (a) 9, (b) 16 and (c) $25 \mathrm{~h}$ (the pristine thickness of Ag foil is $50 \mu \mathrm{m}$ ). (Inset of a) Corresponding low-magnification SEM image. (d-f) The characteristic length scales of nanoporous Ag corresponding to (a-c), respectively. (g) The average ligament size versus the VPA time/alloy phases. (h) The typical XRD pattern of nanoporous Ag dealloyed from AgZn precursor after VPA for $4 \mathrm{~h}$ at $773 \mathrm{~K}$. (Inset of $\mathrm{h}$ ) Optical photograph of the nanoporous Ag foil. (i) The VPA time needed to form $\mathrm{AgZn}_{3}$ at different temperatures and the corresponding average ligament size of nanoporous Ag after dealloying.

stantly, which are accompanied by gradually decreasing and vanishing $\mathrm{AgZn}_{3}$ peaks. Eventually, only the Ag peaks can be detected, indicating the absolute dissolution of $\mathrm{Zn}$ atoms and formation of nanoporous Ag. Noticeably, the transformation from $\mathrm{AgZn}_{3}$ to $\mathrm{Ag}$ is straightforward without the occurrence of other phases such as $\mathrm{Ag}_{5} \mathrm{Zn}_{8}$, $\operatorname{AgZn}$ or $\operatorname{Ag}(\mathrm{Zn})$ whose compositions are within the range of $\mathrm{Ag}$ and $\mathrm{AgZn}_{3}$. Furthermore, the peak positions of $\mathrm{Ag}$ (220) and $\mathrm{AgZn}_{3}$ (110) almost keep invariable during the whole dealloying process (Fig. $5 \mathrm{c}$ ), which robustly supports no solid solution forming.

In order to reveal the ligament coarsening mechanism, $\mathrm{AgZn}_{3}$ foil was immersed in $4 \mathrm{~mol} \mathrm{~L}^{-1} \mathrm{HNO}_{3}$ for different times under free corrosion condition at room temperature. The morphologies of nanoporous Ag show little variation but the ligaments coarsen obviously with increasing dealloying time (Fig. S9). Similar to the iso- thermal grain growth in polycrystalline materials, the relationship between the average ligament size and dealloying time can be described as follows $[5,55,56]$ :

$d(\tau)^{n^{\prime}}=k_{0}^{\prime} \tau \exp \left(-\frac{Q^{\prime}}{R T}\right)=K \tau D_{\mathrm{S}}$

$D_{\mathrm{S}}=D_{0} \exp \left(-\frac{Q^{\prime}}{R T}\right)$,

where $d(\tau)$ is the average ligament size at time $\tau, D_{S}$ is the diffusivity, $k_{0}{ }^{\prime}, K$ and $D_{0}$ are constants, $R$ is the gas constant, $T$ is the dealloying temperature, and $Q^{\prime}$ is the activation energy. $n^{\prime}$ is the coarsening component and related to the mechanism that dominates the coarsening process. A value of $n^{\prime}=3$ standards for bulk diffusion while $n^{\prime}=4$ signifies surface diffusion. The relationship between $\ln [d(\tau)]$ and $\ln \tau$ is plotted in Fig. $5 d$, and the coarsening exponent is calculated to be about 4 according 


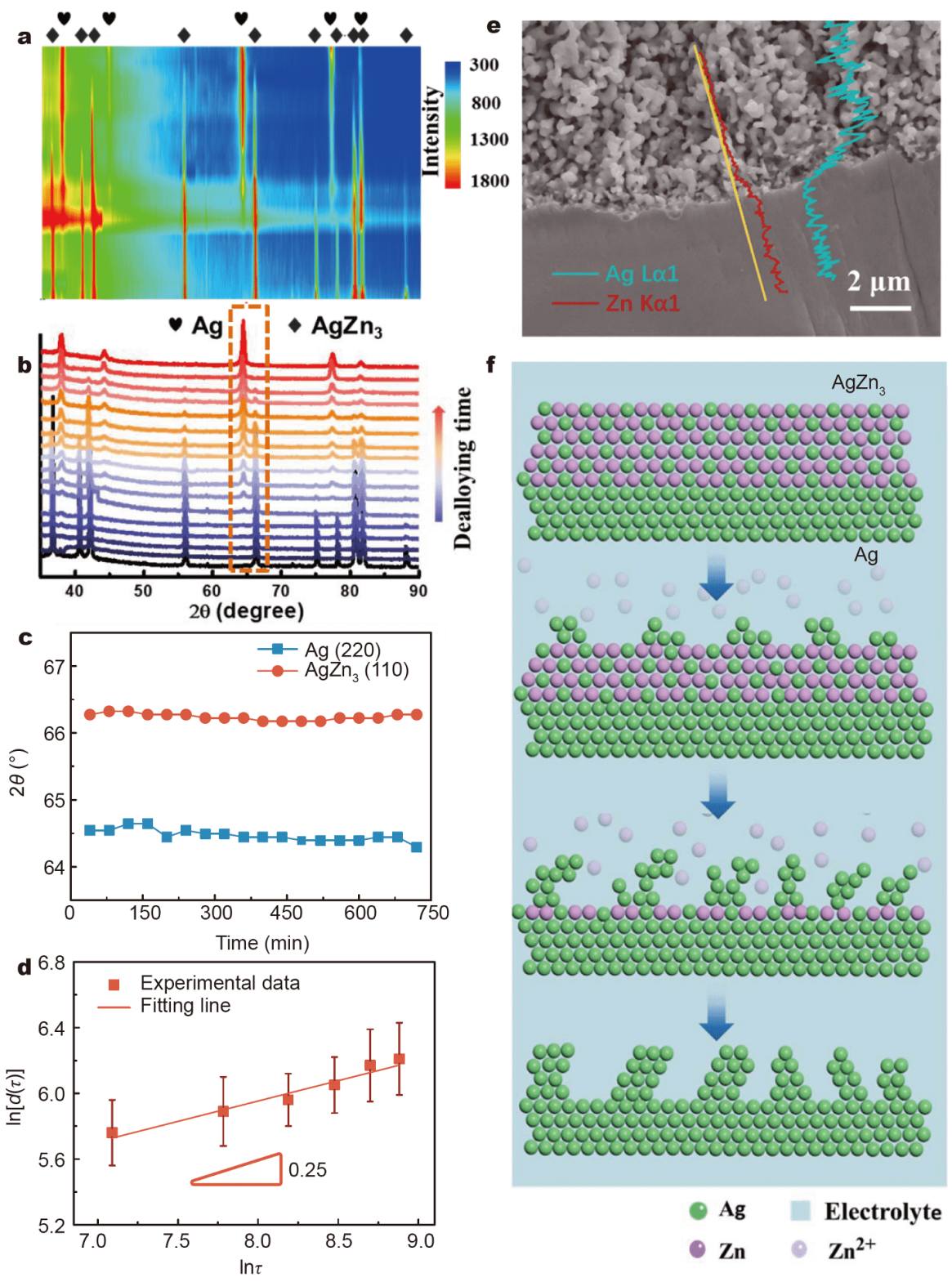

Figure 5 (a) Contour plot and (b) line plot of the in-situ XRD results revealing the chemical dealloying process of $\mathrm{AgZn} \mathrm{n}_{3}$ from the $\mathrm{Ag}$ foil of $50 \mu \mathrm{m}$ (VPA at $773 \mathrm{~K}$ for $25 \mathrm{~h}$ ) at a constant flow of $4 \mathrm{~mol} \mathrm{~L}^{-1} \mathrm{HNO}_{3}$. (c) The relationship between the peak positions and the dealloying time of Ag (220) and $\mathrm{AgZn}_{3}$ (110). (d) The average ligament sizes of nanoporous Ag versus the dealloying time in a logarithmic scale. (e) The SEM image of the interfacial zone of nanoporous $\mathrm{Ag}$ and $\mathrm{AgZn}_{3}$ alloy and the line-scan results after chemical dealloying of $\mathrm{AgZn}_{3}$ alloy in $4 \mathrm{~mol} \mathrm{~L}^{-1} \mathrm{HNO}_{3}$ after $100 \mathrm{~min}$. (f) Schematic illustration of the dealloying process.

to the slope of the fitting line (0.25), which implies that surface diffusion plays a leading role in the dealloying process $[7,57]$. Additionally, the line-scan results reveal that on the boundary between the undealloyed alloy and nanoporous layer, the contents of $\mathrm{Ag}$ and $\mathrm{Zn}$ show an abrupt variation within a small distance of $1 \mu \mathrm{m}$ (Fig. 5e and Fig. S10), illustrating that the dissolution of $\mathrm{Zn}$ is restricted in a small range and the dealloying proceeds almost layer by layer.

Based on the above results and analyses, the dealloying mechanism can be summarized as follows (Fig. 5f). During the early stage of dealloying, the active $\mathrm{Zn}$ atoms dissolve from the surface of the alloy and leave many vacancies dispersed, and thus Ag atoms that remain at the low-coordination sites will diffuse and aggregate toward more stable sites to form islands to minimize the inter- 
facial energy [58]. As the dealloying proceeds, $\mathrm{Zn}$ atoms dissolve constantly from $\mathrm{AgZn}_{3}$ with the electrolyte penetrating the pores and attacking the next layer. During this process, the remaining $\mathrm{Ag}$ atoms agglomerate and rearrange to form nanoporous structure simultaneously, leaving an obvious boundary to distinguish the nanoporous $\mathrm{Ag}$ and the $\mathrm{AgZn}_{3}$ alloy. Particularly, the ligaments on the top layer have already coarsened with increasing dealloying time, compared with the newly formed ligaments at the boundary. Finally, nanoporous $\mathrm{Ag}$ with a bicontinuous ligament-channel structure forms. Movie S1 vividly illustrates the whole dealloying process.

Taking advantage of the large vapor pressure difference between $\mathrm{Zn}$ and other metals such as $\mathrm{Ni}, \mathrm{Co}, \mathrm{Cu}$ and $\mathrm{Au}$ (Fig. S11) [42], the VPA-dealloying strategy can also be utilized to synthesize a series of nanoporous metals and offers the ability to work with irregular shaped surfaces. As for $\mathrm{Ni}, \mathrm{Ni}_{2} \mathrm{Zn}_{11}$ (PDF \# 65-5310) forms on the surface of the pristine Ni foil after VPA for $4 \mathrm{~h}$ with slight surface change (Fig. 6a, b). After VPD, only the Ni phase (PDF \# 65-0380) can be identified and almost no $\mathrm{Zn}$ is left in the as-dealloyed sample (Fig. $6 \mathrm{c}$ and Fig. S12c). The SEM images in Fig. 6d, Fig. S12a and b demonstrate the formation of nanoporous $\mathrm{Ni}$ with an average ligament size of $0.30 \pm 0.06 \mu \mathrm{m}$. Through a similar VPA-VPD procedure, the foil-supported nanoporous Co was successfully fabricated (Fig. 6e and Fig. S13). In addition, nanoporous $\mathrm{Cu}$ with an average ligament size of $100 \mathrm{~nm}$ was obtained through chemical dealloying of the $\mathrm{Cu}$ foil-supported CuZn layer formed by VPA (Fig. $6 f$ and Fig. S14). Besides foils, metallic wires are also suitable for VPA. Here, Ag and $\mathrm{Au}$ wires with different diameters were subjected to VPA. After dealloying, nanoporous Ag and Au wires with distinct length scales were obtained (Fig. 6g, h, Figs S15 and S16), which further reveals the flexibility of the present strategy. Apparently, by tuning the VPA temperature and time to control the thickness of the alloy layer, self-supporting and flexible nanoporous metal wires can be acquired after dealloying. Bulk nanoporous metals show great potentials in actuation $[59,60]$ and are also model materials to explore mechanical properties of three-dimensional porous materials [61]. Notably, bulk porous $\mathrm{Ag}$ can be fabricated by the VPA-dealloying strategy, with a homogeneous ligament-channel structure throughout the entire section (Fig. 6i and Fig. S17).

Because metal vapor can permeate into any space, the VPA-dealloying strategy is applicable to metals with more complicated and irregular shapes like foams. Ni foam is a kind of technologically important engineering material
(Fig. S18), and has extensive applications in electrocatalysis and batteries [62,63]. After the VPA-dealloying treatment, nanoporous structure is formed on the surface of skeletons of $\mathrm{Ni}$ foam (Fig. 6j-1). Encouragingly, the integrity of $\mathrm{Ni}$ foam can be maintained without collapsing, which signifies its potential for practical applications. As summarized in Fig. $6 \mathrm{~m}$, various metals ( $\mathrm{Ag}, \mathrm{Au}$, $\mathrm{Cu}, \mathrm{Co}$ and $\mathrm{Ni}$ ) with kinds of shapes (foils, wires, bulks and even foams) and different macro sizes (from $50 \mu \mathrm{m}$ of Au wire to $2 \mathrm{~mm}$ of Ag bulk) can be manufactured into nanoporous structures through the VPA-dealloying strategy. The insets are corresponding photographs, demonstrating their good self-supporting characteristics. More importantly, the microscopic length scale of nanoporous metals can be well regulated with a range from tens of nanometer to submicron. All these examples convincingly manifest the feasibility and generalizability of the VPA-dealloying strategy, which paves a new way to fabricate the nanoporous structure supported on the metal substrate.

To better show the potential applications of above nanoporous metals, mechanical and electrocatalytic properties were also investigated. Fig. 7a shows the loaddisplacement curves of nanoporous and pristine Ag foils through nanoindentation tests. Compared with the pristine $\mathrm{Ag}$ foil, the shift toward higher displacement of nanoporous $\mathrm{Ag}$ indicates its strength degradation. The hardness of nanoporous $\mathrm{Ag}$ decreases to $0.63 \mathrm{GPa}$ (Fig. 7b) compared with the pristine Ag foil (0.96 GPa), which is consistent with previous reports for nanoporous metals such as $\mathrm{Au}[64,65]$. Moreover, the elastic modulus of nanoporous $\mathrm{Ag}(42 \mathrm{GPa})$ is about half of that of the pristine $\mathrm{Ag}$ foil $(83 \mathrm{GPa})$, indicating its good elastic match which is a key parameter controlling the confinement from the substrate for 'film-substrate' materials [39-41]. It is known that freestanding nanoporous metals almost show no tensile ductility $[34,35]$. Surprisingly, the substrate-supported nanoporous $\mathrm{Ag}$ samples could be subjected to tensile tests and show noticeable ductility (Fig. 7c, d). The substrate-supported Ag with a nanoporous layer of $15 \mu \mathrm{m}$ exhibits an average elongation of $59.6 \% \pm 3.5 \%$, comparable to that of pristine Ag foil $(64.3 \% \pm 6.5 \%)$, implying that the nanoporous layer could synergistically deform with the substrate. With increasing nanoporous layer thickness, the elongation of the substrate-supported nanoporous $\mathrm{Ag}$ obviously decreases. However, the elongation could reach up to $16.1 \% \pm 3.8 \%$ even for the Ag foil with the nanoporous layer of $120 \mu \mathrm{m}$. Moreover, the substrate-supported Ag with nanoporous layers of different thicknesses can be bent freely and re- 

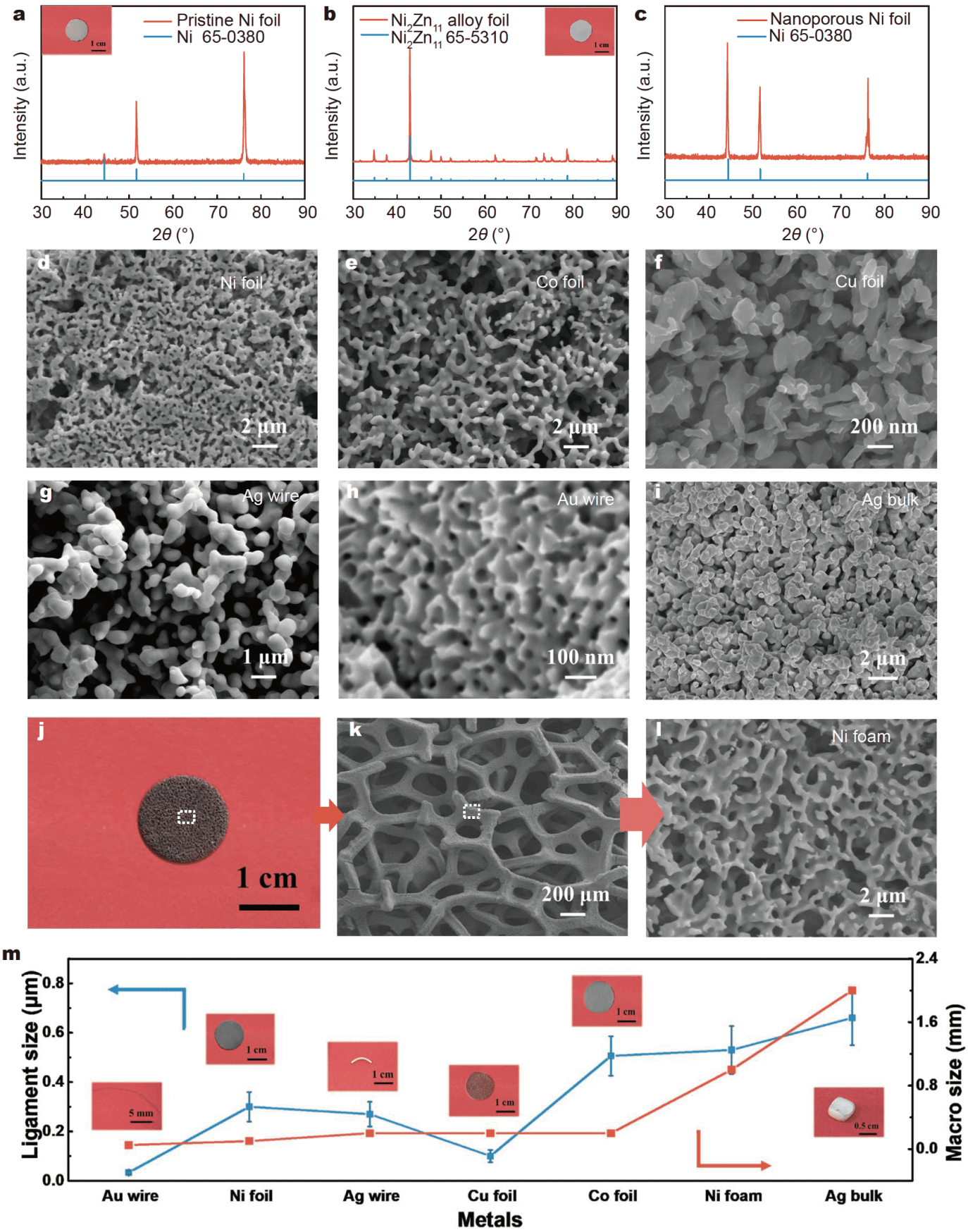

Figure 6 (a-c) XRD patterns of pristine $\mathrm{Ni}$ foil, $\mathrm{Ni}_{2} \mathrm{Zn}_{11}$ alloy foil after VPA at $773 \mathrm{~K}$ for $4 \mathrm{~h}$ and nanoporous Ni foil after VPD at $923 \mathrm{~K}$ for $1 \mathrm{~h}$. The insets of $(a, b)$ are the corresponding optical photographs. (d-i) The SEM images showing the microstructures of nanoporous metals with different shapes fabricated by the VPA-dealloying strategy. The optical photograph (j) and SEM images $(\mathrm{k}, \mathrm{l})$ of nanoporous Ni foam at different magnifications. (m) The average ligament sizes and macro sizes of different nanoporous metals with photographs as the insets.

peatedly without rupture (inset of Fig. 7d), and the nanoporous layer is well bonded to the Ag substrate after the tensile test (Fig. S19). The above results demonstrate that the tensile ductility of the substrate-supported na- noporous metals is much superior to those without substrates, which could be attributed to the good modulus match and excellent adhesion between the nanoporous layer and the substrate with the same element. 

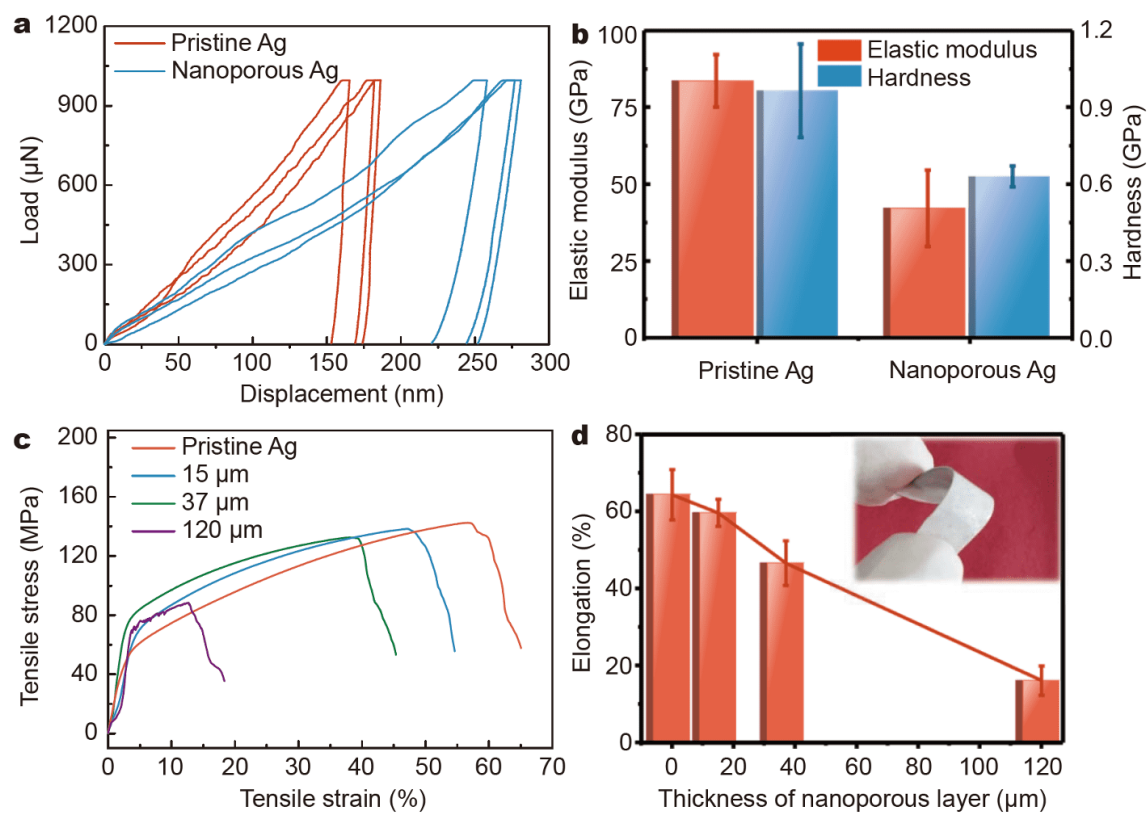

Figure 7 (a) Load-displacement curves and (b) nanomechanical properties of pristine and nanoporous Ag foils. (c) The tensile stress-strain curves of the substrate-supported Ag with nanoporous layers of different thicknesses (15, 37 and $120 \mu \mathrm{m})$. (d) The elongation of the substrate-supported Ag versus the thickness of nanoporous layer. The inset of (d) is the optical photograph of the substrate-supported $\mathrm{Ag}$ with the nanoporous layer of $37 \mu \mathrm{m}$ after bending.

Fig. S20a displays the polarization curves of pristine and nanoporous $\mathrm{Ni}$ foams towards HER in $1 \mathrm{~mol} \mathrm{~L}^{-1}$ $\mathrm{KOH}$ at $5 \mathrm{mV} \mathrm{s}^{-1}$. The nanoporous $\mathrm{Ni}$ foam exhibits an overpotential of $190 \mathrm{mV}$ at $10 \mathrm{~mA} \mathrm{~cm} \mathrm{~cm}^{-2}$, much lower than that of the pristine Ni foam $(289 \mathrm{mV})$. Furthermore, the nanoporous $\mathrm{Ni}$ foam presents a smaller Tafel slope of $100 \mathrm{mV} \mathrm{dec}^{-1}$ (Fig. S20b), exhibiting a superior catalytic activity than the pristine $\mathrm{Ni}$ foam $\left(112 \mathrm{mV} \mathrm{dec}^{-1}\right)$. The remarkable HER performance of the nanoporous $\mathrm{Ni}$ foam is associated with the unique hierarchical structure containing macro- and nano-sized pores, which can promote the mass transport and provide more active sites.

\section{CONCLUSIONS}

In summary, we report a universal and flexible VPAdealloying strategy to fabricate nanoporous layers supported on the metal substrates with the same element. Selecting the Ag-Zn system as an example, by tuning the VPA time and temperature, the thickness and microstructure control over nanoporous layers can be realized combining with subsequent dealloying. In particular, the growth of AgZn during VPA is controlled by the reaction-controlled mechanism, and the chemical dealloying of $\mathrm{AgZn}_{3}$ to form nanoporous $\mathrm{Ag}$ is straightforward without the occurrence of intermediate/metastable phases and governed by surface diffusion. Additionally, various metals with different macro sizes and shapes (here Ag foil, Ag wire, Ag bulk, $\mathrm{Ni}$ foil, $\mathrm{Co}$ foil, $\mathrm{Cu}$ foil, $\mathrm{Au}$ wire and $\mathrm{Ni}$ foam) can be fabricated into nanoporous structures with good self-supporting properties by the VPAdealloying strategy. More importantly, the good modulus match and the excellent interfacial adhesion between the nanoporous layer and the substrate account for the noticeable tensile ductility of the substrate-supported nanoporous Ag, which will greatly push forward practical applications of nanoporous metals. Apart from $\mathrm{Zn}$, it can be anticipated that other metals with high vapor pressures such as $\mathrm{Mg}$ and $\mathrm{Cd}$ can also be applied as sacrificing elements in this strategy to further extend the range of nanoporous metals.

Received 9 September 2020; accepted 20 October 2020; published online 6 January 2021

1 Coaty $\mathrm{C}$, Zhou $\mathrm{H}$, Liu $\mathrm{H}$, et al. A scalable synthesis pathway to nanoporous metal structures. ACS Nano, 2018, 12: 432-440

2 Ding Y, Kim YJ, Erlebacher J. Nanoporous gold leaf: “Ancient technology"/advanced material. Adv Mater, 2004, 16: 1897-1900

3 Hakamada M, Mabuchi M. Fabrication, microstructure, and properties of nanoporous $\mathrm{Pd}, \mathrm{Ni}$, and their alloys by dealloying. Crit Rev Solid State Mater Sci, 2013, 38: 262-285

4 Li ZQ, Li BQ, Qin ZX, et al. Fabrication of porous Ag by dealloying of $\mathrm{Ag}-\mathrm{Zn}$ alloys in $\mathrm{H}_{2} \mathrm{SO}_{4}$ solution. J Mater Sci, 2010, 45: 64946497 
5 Lu Z, Li C, Han J, et al. Three-dimensional bicontinuous nanoporous materials by vapor phase dealloying. Nat Commun, 2018, 9: 276

6 Zhang Q, Zhang Z. On the electrochemical dealloying of Al-based alloys in a $\mathrm{NaCl}$ aqueous solution. Phys Chem Chem Phys, 2010, 12: 1453-1472

7 Bhushan B, Murty BS, Mondal K. Dealloying kinetics and mechanism of porosity evolution in mechanically alloyed $\operatorname{Ag}_{25} \mathrm{Zn}_{75}$ powder particles. Corros Sci, 2018, 139: 155-162

8 Kucheyev SO, Hayes JR, Biener J, et al. Surface-enhanced Raman scattering on nanoporous Au. Appl Phys Lett, 2006, 89: 053102

9 Hayes JR, Hodge AM, Biener J, et al. Monolithic nanoporous copper by dealloying Mn-Cu. J Mater Res, 2006, 21: 2611-2616

10 Erlebacher J, Aziz MJ, Karma A, et al. Evolution of nanoporosity in dealloying. Nature, 2001, 410: 450-453

11 Pugh DV, Dursun A, Corcoran SG. Formation of nanoporous platinum by selective dissolution of $\mathrm{Cu}$ from $\mathrm{Cu}_{0.75} \mathrm{Pt}_{0.25}$. J Mater Res, 2011, 18: 216-221

12 Shui JI, Chen C, Li JCM. Evolution of nanoporous Pt-Fe alloy nanowires by dealloying and their catalytic property for oxygen reduction reaction. Adv Funct Mater, 2011, 21: 3357-3362

13 Li C, Zhang T, Zhang M, et al. Fabrication of fine spongy nanoporous Ag-Au alloys with improved catalysis properties. Prog Nat Sci-Mater Int, 2017, 27: 658-663

14 Zhang C, Xie Z, He X, et al. Fabrication and characterization of nanoporous $\mathrm{Cu}-\mathrm{Sn}$ intermetallics via dealloying of ternary $\mathrm{Mg}$ $\mathrm{Cu}-\mathrm{Sn}$ alloys. CrystEngComm, 2018, 20: 6900-6908

15 Koczkur K, Yi Q, Chen A. Nanoporous Pt-Ru networks and their electrocatalytical properties. Adv Mater, 2007, 19: 2648-2652

16 Chen L, Guo H, Fujita T, et al. Nanoporous PdNi bimetallic catalyst with enhanced electrocatalytic performances for electrooxidation and oxygen reduction reactions. Adv Funct Mater, 2011, 21: 4364-4370

17 Wittstock A, Zielasek V, Biener J, et al. Nanoporous gold catalysts for selective gas-phase oxidative coupling of methanol at low temperature. Science, 2010, 327: 319-322

18 Zielasek V, Jürgens B, Schulz C, et al. Gold catalysts: Nanoporous gold foams. Angew Chem Int Ed, 2006, 45: 8241-8244

19 Gan L, Heggen M, O’Malley R, et al. Understanding and controlling nanoporosity formation for improving the stability of bimetallic fuel cell catalysts. Nano Lett, 2013, 13: 1131-1138

20 Weissmüller J, Viswanath RN, Kramer D, et al. Charge-induced reversible strain in a metal. Science, 2003, 300: 312-315

21 Biener J, Wittstock A, Zepeda-Ruiz LA, et al. Surface-chemistrydriven actuation in nanoporous gold. Nat Mater, 2009, 8: 47-51

22 Zhang L, Lang X, Hirata A, et al. Wrinkled nanoporous gold films with ultrahigh surface-enhanced Raman scattering enhancement. ACS Nano, 2011, 5: 4407-4413

23 Choi JW, McDonough J, Jeong S, et al. Stepwise nanopore evolution in one-dimensional nanostructures. Nano Lett, 2010, 10: 1409-1413

24 Peng Z, Freunberger SA, Chen Y, et al. A reversible and higher-rate Li-O ${ }_{2}$ battery. Science, 2012, 337: 563-566

25 Chen M, Mandal J, Ye Q, et al. A scalable dealloying technique to create thermally stable plasmonic nickel selective solar absorbers. ACS Appl Energy Mater, 2019, 2: 6551-6557

26 Dai S, Wu J, Zhang Y, et al. Effect of alloy composition on morphology, structure, and electrochemical properties of porous nickel. Ionics, 2017, 24: 597-603

27 Zhang Q, Wang X, Qi Z, et al. A benign route to fabricate nano- porous gold through electrochemical dealloying of $\mathrm{Al}-\mathrm{Au}$ alloys in a neutral solution. Electrochim Acta, 2009, 54: 6190-6198

28 Zhang C, Sun J, Xu J, et al. Formation and microstructure of nanoporous silver by dealloying rapidly solidified $\mathrm{Zn}-\mathrm{Ag}$ alloys. Electrochim Acta, 2012, 63: 302-311

29 Wada T, Geslin PA, Kato H. Preparation of hierarchical porous metals by two-step liquid metal dealloying. Scripta Mater, 2018, 142: 101-105

30 McCue I, Ryan S, Hemker K, et al. Size effects in the mechanical properties of bulk bicontinuous $\mathrm{Ta} / \mathrm{Cu}$ nanocomposites made by liquid metal dealloying. Adv Eng Mater, 2016, 18: 46-50

31 Joo SH, Bae JW, Park WY, et al. Beating thermal coarsening in nanoporous materials via high-entropy design. Adv Mater, 2020, 1906160

32 Chen Q, Sieradzki K. Spontaneous evolution of bicontinuous nanostructures in dealloyed Li-based systems. Nat Mater, 2013, 12: 1102-1106

33 Han J, Li C, Lu Z, et al. Vapor phase dealloying: A versatile approach for fabricating 3D porous materials. Acta Mater, 2019, 163 : 161-172

34 Li R, Sieradzki K. Ductile-brittle transition in random porous Au. Phys Rev Lett, 1992, 68: 1168-1171

35 Jin HJ, Kurmanaeva L, Schmauch J, et al. Deforming nanoporous metal: Role of lattice coherency. Acta Mater, 2009, 57: 2665-2672

36 Ji Y, Xing Y, Zhou F, et al. The mechanical characteristics of monolithic nanoporous copper and its composites. Adv Eng Mater, 2018, 20: 1800574

37 Biener J, Hodge AM, Hayes JR, et al. Size effects on the mechanical behavior of nanoporous Au. Nano Lett, 2006, 6: 2379-2382

38 Wang K, Weissmüller J. Composites of nanoporous gold and polymer. Adv Mater, 2013, 25: 1280-1284

39 Xiang Y, Li T, Suo Z, et al. High ductility of a metal film adherent on a polymer substrate. Appl Phys Lett, 2005, 87: 161910

40 Lu N, Wang X, Suo Z, et al. Metal films on polymer substrates stretched beyond 50\%. Appl Phys Lett, 2007, 91: 221909

41 Fang TH, Li WL, Tao NR, et al. Revealing extraordinary intrinsic tensile plasticity in gradient nano-grained copper. Science, 2011, 331: 1587-1590

42 Lide DR. CRC Handbook of Chemisty And Physics ( $85^{\text {nd }}$ ed). Boca Raton: CRC press. 2005

43 Friedman JR, Garay JE, Anselmi-Tamburini U, et al. Modified interfacial reactions in $\mathrm{Ag}-\mathrm{Zn}$ multilayers under the influence of high DC currents. Intermetallics, 2004, 12: 589-597

44 Yang W, Ma W, Zhang Z, et al. Ligament size-dependent electrocatalytic activity of nanoporous Ag network for $\mathrm{CO}_{2}$ reduction. Faraday Discuss, 2018, 210: 289-299

$45 \mathrm{Su} \mathrm{L}$, Gan YX. Nanoporous $\mathrm{Ag}$ and $\mathrm{Ag}-\mathrm{Sn}$ anodes for energy conversion in photochemical fuel cells. Nano Energy, 2012, 1: 159163

46 Zhang Y, Liu L, Shi L, et al. Enhancing $\mathrm{CO}_{2}$ electroreduction on nanoporous silver electrode in the presence of halides. Electrochim Acta, 2019, 313: 561-569

47 Andrews KW, Davies HE, Hume-Rothery W, et al. The equilibrium diagram of the system silver-zinc. Proc R Soc Lond, 1941, A177: 149-167

48 Chen D, Zhang $\mathrm{T}$, Wang $\mathrm{Y}$, et al. Wear resistance and microstructure of the nitriding layer formed on 2024 aluminum alloy by plasma-enhanced nitriding at different nitriding times. Mater Res Express, 2019, 6: 066405

49 Assari AH, Eghbali B. Microstructure and kinetics of intermetallic 
phase formation during solid state diffusion bonding in bimetal Ti/ Al. Phys Met Metallogr, 2019, 120: 260-268

50 Zhao Y, Li J, Qiu R, et al. Growth characterization of intermetallic compound at the $\mathrm{Ti} / \mathrm{Al}$ solid state interface. Materials, 2019, 12: 472

51 Xu L, Cui YY, Hao YL, et al. Growth of intermetallic layer in multi-laminated Ti/Al diffusion couples. Mater Sci Eng-A, 2006, 435: 638-647

52 Foadian $\mathrm{F}$, Soltanieh $\mathrm{M}$, Adeli M, et al. The kinetics of $\mathrm{TiAl}_{3}$ formation in explosively welded Ti-Al multilayers during heat treatment. Metall Mater Trans B, 2016, 47: 2931-2937

53 Liu LZ, Jin HJ. Scaling equation for the elastic modulus of nanoporous gold with "fixed" network connectivity. Appl Phys Lett, 2017, 110: 211902

54 Seker E, Gaskins JT, Bart-Smith H, et al. The effects of post-fabrication annealing on the mechanical properties of freestanding nanoporous gold structures. Acta Mater, 2007, 55: 4593-4602

55 Qian LH, Chen MW. Ultrafine nanoporous gold by low-temperature dealloying and kinetics of nanopore formation. Appl Phys Lett, 2007, 91: 083105

56 Zhou F, Lee J, Lavernia EJ. Grain growth kinetics of a mechanically milled nanocrystalline Al. Scripta Mater, 2001, 44: 2013-2017

$57 \mathrm{Li} \mathrm{Z,} \mathrm{Lu} \mathrm{X,} \mathrm{Qin} \mathrm{Z.} \mathrm{Formation} \mathrm{of} \mathrm{nanoporous} \mathrm{silver} \mathrm{by} \mathrm{dealloying}$ $\mathrm{Ag}_{22} \mathrm{Zn}_{78}$ alloy at low temperature in $\mathrm{H}_{2} \mathrm{SO}_{4}$. Int J Electrochem Sci, 2013, 8: 3564-3571

58 Liu P, Chen Q, Ito Y, et al. Dealloying kinetics of AgAu nanoparticles by in situ liquid-cell scanning transmission electron microscopy. Nano Lett, 2020, 20: 1944-1951

59 Zhang J, Wang Y, Si C, et al. Electrochemical actuation behaviors of bulk nanoporous palladium in acid and alkaline solutions. Electrochim Acta, 2016, 220: 91-97

60 Jin HJ, Wang XL, Parida S, et al. Nanoporous $\mathrm{Au}-\mathrm{Pt}$ alloys as large strain electrochemical actuators. Nano Lett, 2010, 10: 187-194

61 Briot NJ, Kennerknecht T, Eberl C, et al. Mechanical properties of bulk single crystalline nanoporous gold investigated by millimetrescale tension and compression testing. Philos Mag, 2014, 94: 847866

62 Cai J, Xu J, Wang J, et al. Fabrication of three-dimensional nanoporous nickel films with tunable nanoporosity and their excellent electrocatalytic activities for hydrogen evolution reaction. Int J Hydrogen Energy, 2013, 38: 934-941

$63 \mathrm{He} \mathrm{H,} \mathrm{Liu} \mathrm{H,} \mathrm{Liu} \mathrm{F,} \mathrm{et} \mathrm{al.} \mathrm{Structures} \mathrm{and} \mathrm{electrochemical} \mathrm{properties}$ of amorphous nickel sulphur coatings electrodeposited on the nickel foam substrate as hydrogen evolution reaction cathodes. Surf Coat Technol, 2006, 201: 958-964

64 Kim YC, Gwak EJ, Ahn SM, et al. Indentation size effect in nanoporous gold. Acta Mater, 2017, 138: 52-60

65 Hakamada M, Mabuchi M. Mechanical strength of nanoporous gold fabricated by dealloying. Scripta Mater, 2007, 56: 1003-1006

Acknowledgements The authors gratefully acknowledge the financial support by the National Natural Science Foundation of China (51871133 and 51671115), Taishan Scholar Foundation of Shandong Province, the program of Jinan Science and Technology Bureau and the Department of Science and Technology of Shandong Province.

Author contributions Zhang $\mathrm{Z}$ conceived the idea and designed the experiments. Shi $Y$ prepared the samples, analyzed the data, performed the measurements and wrote the manuscript. Zhang Y performed the SEM characterizations. Qin J took part in the data analysis.
Conflict of interest The authors declare that they have no known competing financial interests or personal relationships that could have appeared to influence the work reported in this paper.

Supplementary information Experimental details and supporting data are available in the online version of the paper.

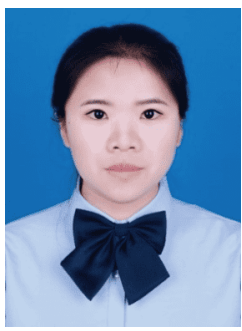

Yujun Shi received her Bachelor degree in 2017 from Central South University. She is currently pursuing her $\mathrm{PhD}$ under the supervision of Prof. Zhonghua Zhang at the School of Materials Science and Engineering, Shandong University. Her research is mainly focused on fabrication and applications of nanoporous metals.

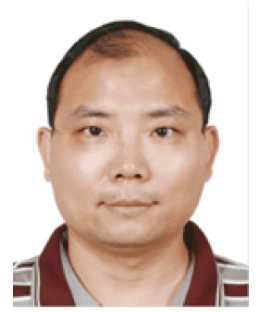

Zhonghua Zhang received his $\mathrm{PhD}$ degree in 2003 from the School of Materials Science and Engineering, Shandong University, Jinan, China. During 2004-2005, he worked as an Alexander von Humboldt postdoctoral research fellow at the Institute of Materials, Ruhr University Bochum, Germany. At the end of 2005, he got a full professor position in Shandong University. At present, his research interests mainly focus upon dealloying mechanisms, dealloying-driven nanoporous metals, metal/metal oxide nanocomposites, and their applications in energy and environment-related fields.

\section{通过气相合金化-脱合金化实现对纳米多孔金属 宏观/微观结构的耦合调控}

石玉君, 张颖, 秦敬玉, 张忠华 ${ }^{*}$

摘要 具有双连续韧带-孔隙结构的纳米多孔金属在催化、电催 化、驱动、能源储存和转化领域起着越来越重要的作用. 然而, 纳 米多孔金属的本征脆性一直是制约其实际应用的“阿喀琉斯之踵”. 针对这个问题, 本文利用不同金属的蒸气压差, 提出了一种具有普 适性的气相合金化(VPA)-脱合金策略来制备同种金属基底支撑的 纳米多孔层. 通过调节VPA的时间和温度, 结合不同的脱合金方式, 可以实现对纳米多孔层宏观厚度和微观结构的调控. 此外, 具有不 同宏观尺寸和形状的金属, 如 $\mathrm{Ag}, \mathrm{Au}, \mathrm{Cu}, \mathrm{Co}$ 和 $\mathrm{Ni}$, 均可以通过此 策略制备成纳米多孔结构. 更重要的是, 由于基底对纳米多孔层的 支撑作用，其拉伸塑性得到了大幅度的提高; 获得的纳米多孔金属 应用于析氢反应时也表现出良好的催化性能. 本文研究结果表明 气相合金化-脱合金策略在实际应用中具有极大的潜力. 